\title{
The Chicken Thigh Adductor Profundus Free Muscle Flap: A Novel Validated Non-Living Microsurgery Simulation Training Model
}

\author{
Georgios Pafitanis, Yasmine Serrar, Maria Raveendran, Ali Ghanem, Simon Myers \\ Academic Plastic Surgery, The Royal London Hospital, Barts Health NHS Trust, Queen Mary University of London, London, UK
}

Background Simulation training is becoming an increasingly important component of skills acquisition in surgical specialties, including Plastic Surgery. Non-living simulation models have an established place in Plastic Surgical microsurgery training, and support the principles of replacement, reduction and refinement of animal use. A more sophisticated version of the basic chicken thigh microsurgery model has been developed to include dissection of a type 1-muscle flap and is described and validated here.

Methods A step-by-step dissection guide on how to perform the chicken thigh adductor profundus free muscle flap is demonstrated. Forty trainees performed the novel simulation muscle flap on the last day of a 5-day microsurgery course. Pre- and post-course microvascular anastomosis assessment, along with micro dissection and end product (anastomosis lapse index) assessment, demonstrated skills acquisition.

Results The average time to dissect the flap by novice trainees was $82 \pm 24$ minutes, by core trainees $90 \pm 24$ minutes, and by higher trainees $64 \pm 21$ minutes $(P=0.013)$. There was a statistically significant difference in the time to complete the anastomosis between the three levels of training $(P=0.001)$ and there was a significant decrease in the time taken to perform the anastomosis following course completion $(\mathrm{P}<0.001)$. Anastomosis lapse index scores improved for all cohorts with post-test average anastomosis lapse index score of $3 \pm 1.4$ $(\mathrm{P}<0.001)$.

Conclusions The novel chicken thigh adductor profundus free muscle flap model demonstrates face and construct validity for the introduction of the principles of free tissue transfer. The low cost, constant, and reproducible anatomy makes this simulation model a recommended addition to any microsurgical training curriculum.

Keywords Microsurgery / Education / Flap
Correspondence: Georgios Pafitanis Academic Plastic Surgery, The Royal London Hospital, Barts Health NHS Trust, Queen Mary University of London, 4 Newark Street, Whitechapel, E12AT, London, UK Tel: +44-7948732752 Fax: +44-7948732752 E-mail: g.pafitanis@qmul.ac.uk

This manuscript was presented during the 2016 ASRM Annual Meeting, on January 16-19, 2016 in Scottsdale, AZ, USA.

This article contains Supplemental Video S1 and Video S2.

No potential conflict of interest relevant to this article was reported.

Received: 29 Dec 2016 • Revised: 1 Mar 2017 Accepted: 5 Apr 2017

pISSN: 2234-6163・ elSSN: 2234-6171 • https://doi.org/10.5999/aps.2017.44.4.293・ Arch Plast Surg 2017;44:293-300

\section{INTRODUCTION}

Simulation training is increasingly relevant to skills acquisition and the microsurgery learning curve [1]. Current literature sup- ports simulation training in living and non-living models prior to attempting free tissue transfer in the clinical environment [2]. The initial step in microsurgery skill acquisition is usually achieved by undertaking a basic non-living, living, or combined 
non-living/living course [1,3]. Non-living models require fewer resources [1], but their main advantage is ethical, addressing replacement, reduction and refinement (3Rs) of animal use $[2,4,5]$. The biological non-living models described [5], include: turkey wings and neck, and fresh or cryopreserved rat vessels $[1,6-8]$. The fresh chicken model remains one of the most widely used and easily accessible models [9,10]. Several parts of the chicken anatomy provide high training face validity (thigh, wing and foot) [11-14]. The chicken thigh femoral vessels have good handling properties and a caliber that is broadly comparable with clinical microvascular pedicles [11]. In a basic microsurgery course curriculum, trainees are introduced to vessel micro-dissection and microvascular anastomosis $[1,3]$. However, a biological non-living simulation model for free flap dissection, transfer and anastomosis has yet to be described. We describe and validate a non-living free flap dissection, transfer and anastomosis simulation training model in the chicken thigh based on the adductor profundus muscle which would seem an appropriate training model prior, for example, to raising and anastomosing a groin flap in the live rat.

\section{METHODS}

Ten chicken thighs (Fig. 1) were initially dissected to identify the main vascular tree of the femoral pedicles and its muscle and skin perforator branches. All specimens were assessed for anatomical variants, dissection planes, vessels, and perforator caliber. A muscular branch supplying the adductor profundus mus-

\section{Fig. 1. Chicken thigh medial (inner) surface}

Chicken thigh is accessed through medial (inner) surface of the specimen to expose the medial thigh muscles (c, d) (red, violet). (a) Remnant abdominal muscle, (b) skin paddle.

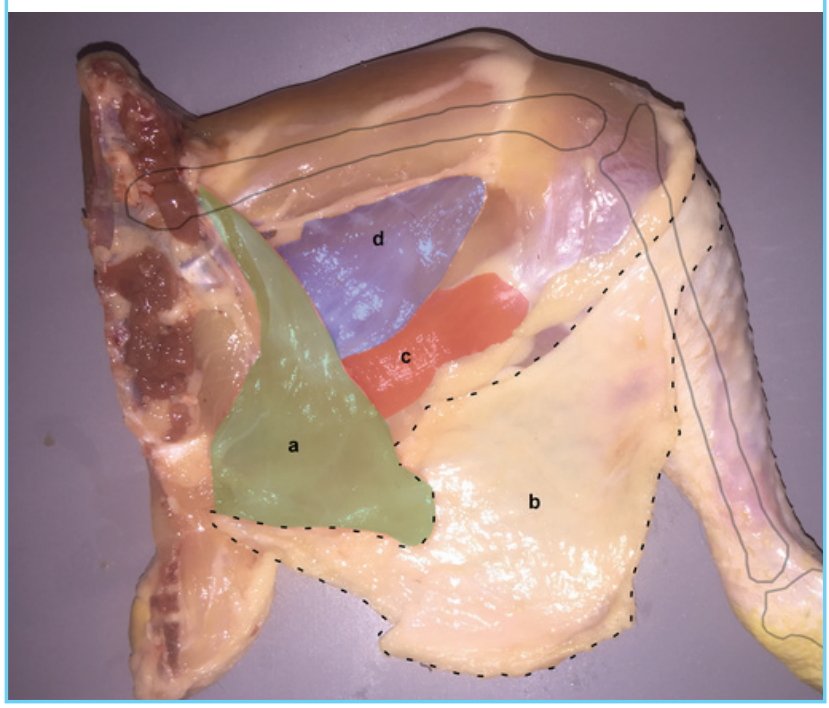

cle flap analogous to a Mathes and Nahai [15] type I muscular flap was a consistent finding in all samples. All trainees, including medical students, core surgical trainees and higher specialty trainees, who undertook a 5-day non-living microsurgery-training course between 2014 to 2016, were trained to dissect, raise and transfer the adductor profundus free muscle flap in the chicken thigh on the last day of the course. The non-living course, in our institution starts with basic skills to set up the microscope, instrument handling, two and three dimensional suturing using gauze and silicon tube and introduced the chicken thigh training model on day 2. All trainees complete the course after completing more than 20 anastomosis. Trainees were as-

Table 1. The chicken thigh adductor profundus free muscle flap: a step-by-step guide

Step 1: Chicken thigh is accessed through medial (inner) surface of the specimen.

Step 2: The remnant abdominal muscle is retracted medially (a) (green) and the skin paddle inferio-laterally (b) to expose the medial thigh muscles (c, d) (red, violet) (Fig. 1).

Step 3: Blunt dissection in the space bound by the flexor cruris medialis inferiorly (c) (red), the adductor profundus (AP) (d) (violet) superiorly and the femoro-cruralis (f) (yellow) laterally facilitate the identification of the muscular branch (e) (Fig. 2).

Step 4: Careful dissection inferior to adductor profundus (violet) to reveal the entire course of the muscle branch (e) (Fig. 2).

Step 5: The medial border of adductor profundus (violet) muscle is divided (Fig. 3).

Step 6: Femoro-cruralis (f) (yellow) is divided inferio-laterally and elevated superiorly to reveal the main femoral source vessels (blue and red lines over femoral vein and artery respectively). The AP muscle (violet) is then freed by dividing its bony insertion (g) (white line) along with its septal attachment to the vastus lateralis (h) (green) superiorly (Fig. 4).

Step 7: AP muscular pedicle is then carefully dissected towards femoral source vessels with ligation of all other branches (Fig. 5).

Step 8: The femoral source pedicle is further dissected distally to reach approximately $5-6 \mathrm{~cm}$ of pedicle length (Fig. 6).

Step 9: Distal muscular branch to the flexor cruris medialis (red) inferiorly is ligated (Figs. 5 \& 6).

Step 10: The femoral source vessels are divided around the flap's pedicle (yellow lines) to free the AP muscle (violet) free flap (Fig. 6 insert). 
sessed with an end-to-end femoral arterial anastomosis before and after completion of the course. A step-by-step guide was provided to the trainees on how to perform the chicken thigh adductor profundus free muscle flap on day 5 of the course using microscopic magnification $(\times 6-\times 25)$ (Table 1, Figs. 1-6). All trainees raised the free muscle flap, microdissected the vascular pedicle, prepared the recipient vessels, and performed the

\section{Fig. 2. Adductor profundus muscle branch}

Blunt dissection in the space bound by the flexor cruris medialis inferiorly (c) (red), the adductor profundus (AP) (d) (violet) superiorly and the femoro-cruralis (f) (yellow) laterally facilitate the identification of the muscular branch (e). Careful dissection inferior to adductor profundus (violet) to reveal the entire course of the muscle branch.

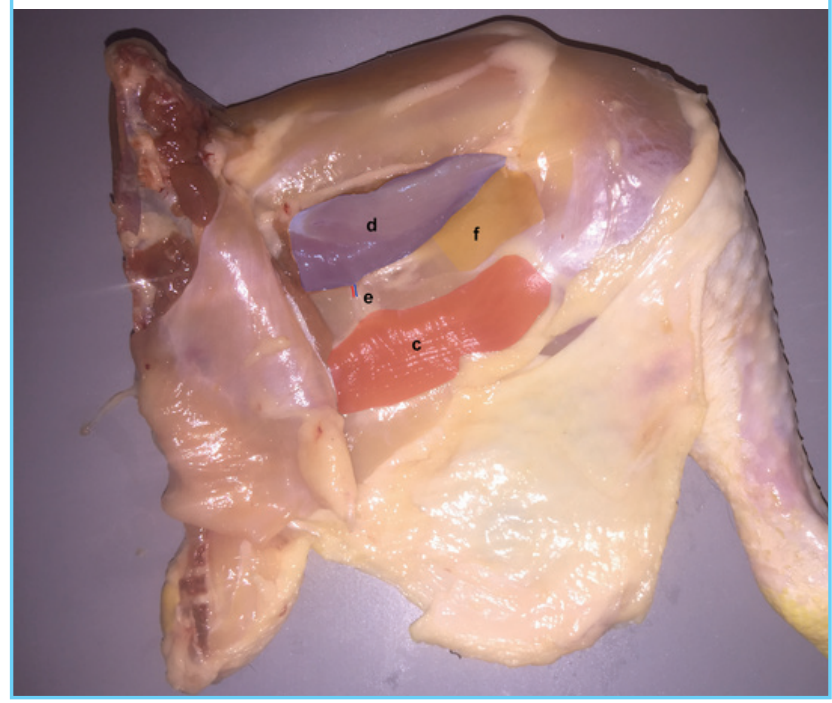

\section{Fig. 3. Division of proximal muscle border}

The medial border of adductor profundus (d) (violet) muscle is divided. (c) Flexor cruris medialis, (f) femoro-cruralis.

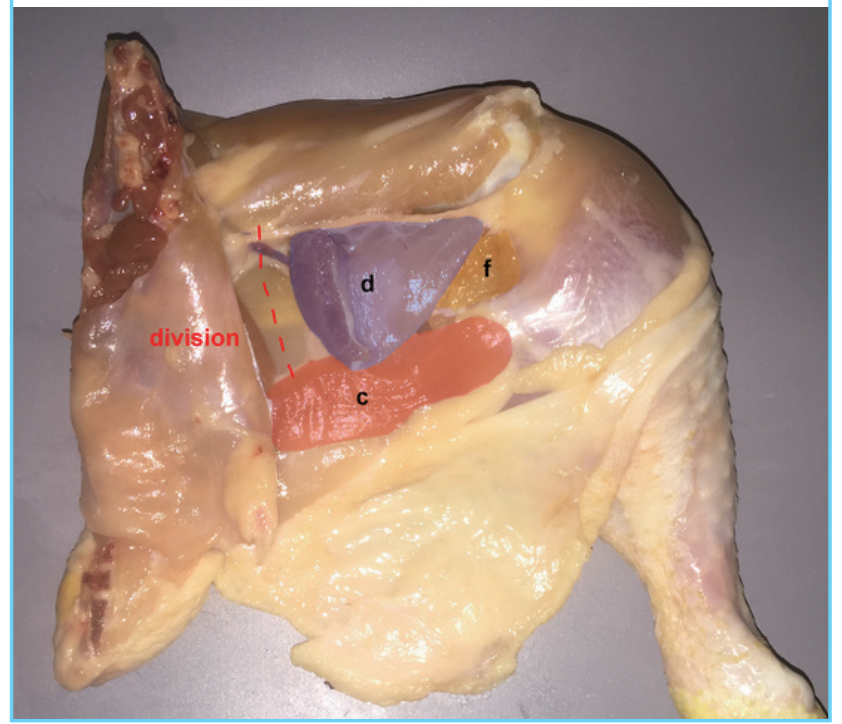

arterial and venous microanastomosis based on the ischiatic vessels of the chicken thigh. The time to complete a non-living chicken arterial anastomosis and an end product assessment using the validated anastomosis lapse index (ALI) score were recorded before and after completion of the course [16]. The

\section{Fig. 4. Pedicle Dissection}

Femoro-cruralis (f) (yellow) is divided inferio-laterally and elevated superiorly to reveal the main femoral source vessels (blue and red lines over femoral vein and artery respectively). The adductor profundus (AP) muscle (d) (violet) is then freed by dividing its bony insertion (g) (white line) along with its septal attachment to the vastus lateralis (h) (green) superiorly. (c) Flexor cruris medialis, (e) muscle branch.

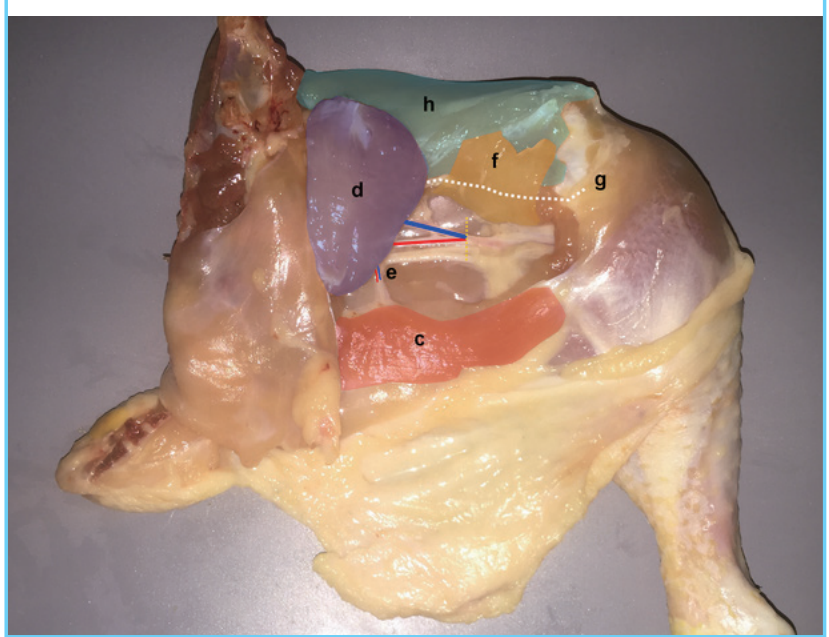

\section{Fig. 5. Flexor cruris medialis branch}

Adductor profundus muscular pedicle is then carefully dissected towards femoral source vessels with ligation of all other branches. Distal muscular branch to the flexor cruris medialis (red) inferiorly is ligated.

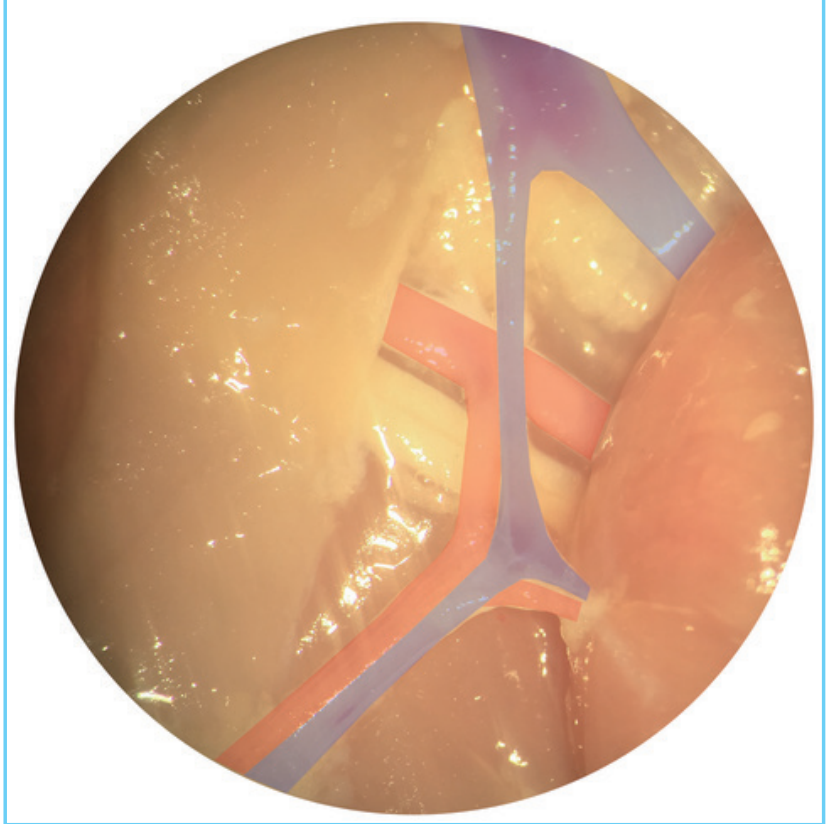




\section{Fig. 6. Chicken thigh adductor profundus elevated}

The femoral source pedicle is further dissected distally to reach approximately $5-6 \mathrm{~cm}$ of pedicle length. The femoral source vessels are divided around the flap's pedicle (yellow lines) to free the adductor profundus (d) muscle (violet) free flap. (a) Remnant abdominal muscl, (c) flexor cruris medialis, (f) femoro-cruralis, (h) vastus lateralis.

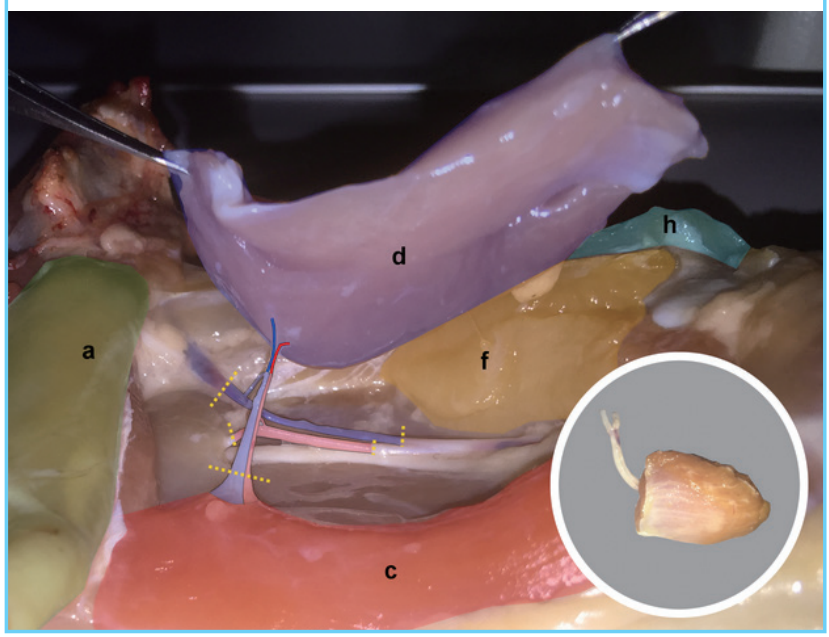

time to raise the abductor profundus flap was recorded, and all surgeons completed a feedback questionnaire on the face validity of this training model.

Data analysis was performed using IBM SPSS Statistics ver. 21 (IBM Cor., Somers, NY, USA). Differences between groups were tested using one-way analysis of variance (ANOVA) for parametric variables and the Kruksal-Wallis one-way analysis of variance for non-parametric variables. Differences between pretest and post-test were analysed using the paired Student's t-test for parametric variables and the Wilcoxon signed-ranks test for non-parametric paired variables. Averages were reported as mean \pm standard deviation (minimum-maximum) for parametric variables with the Mean being substituted by the Median for nonparametric variables. Statistical significance was accepted with $\mathrm{P} \leq 0.05$.

\section{RESULTS}

Forty trainees completed the 5-day course during the study period. These comprised of 11 undergraduate medical students (novices), 12 core surgical trainees, and 17 higher specialty trainees.

\section{Flap dissection}

$87.5 \%$ of trainees strongly agreed that the model was good for understanding the principles of free tissue transfer. $77.5 \%$ strongly agreed that the model sufficiently simulates free tissue dissection and transfer in a live model. All trainees strongly or moder- ately agreed that the model adequately facilitates skill acquisition relevant to free flap dissection and microvascular anastomosis. Finally, 90\% of trainees strongly recommended practicing the chicken thigh free flap model prior to attending living model courses. The average time to dissect the flap was $77 \pm 25$ (32130) minutes. The average time to dissect the flap by novice trainees was $82 \pm 24$ minutes, by core trainees $90 \pm 24$ minutes, and by higher trainees $64 \pm 21$ minutes. There was a statistically significant difference in flap dissection time between the three levels of training ANOVA $(\mathrm{F}[2,37]=4.86376, \mathrm{P}=0.013)$.

\section{Microvascular anastomosis}

Time to perform the anastomosis

The average time to perform the arterial anastomosis on the first day of the course (pre-test) was $31 \pm 15$ (15-72) minutes. For novice trainees, the pre-test was $46 \pm 18$ minutes, for core trainees $31 \pm 12$ minutes and for higher trainees $27 \pm 9$ minutes. There was a statistically significant difference in the time to complete the anastomosis between the three levels of training $(\mathrm{F}$ $[2,37]=7.6771, P=0.001)$. For the post-test, the average time to perform the arterial anastomosis for the novices was $29 \pm 12$ minutes, for the core trainees was $22 \pm 7$ minutes and for the higher trainees was $16 \pm 5$ minutes. All groups showed a significant decrease in the time taken to perform the anastomoses following the completion of the course (paired sample Student's ttest, $\mathrm{P}<0.001$ ).

\section{End product assessment}

The average ALI score for the anastomosis performed before the course (pre-test) for all trainees was $5 \pm 1.4$. For novice trainees, the pre-test ALI score was $5 \pm 1.4$ errors, for core trainees $4.5 \pm 1.5$ errors, and for higher trainees $5 \pm 1.3$ errors. After completion of the course, ALI scores improved for all cohorts with post-test average ALI score of $3 \pm 1.4$ (Wilcoxon Signed Rank Test $\mathrm{Z}=-4.52, \mathrm{P}<0.001)$. For the novice trainees the average ALI score following the course was $3 \pm 1.4$, for core trainees $4 \pm 1.4$, and for higher trainees $2 \pm 0.9$. There was a statistically significant difference in the ALI score between the three cohorts for the post-test $(\mathrm{P}=0.008)$, although not for the pretest $(\mathrm{P}=0.62)$.

\section{DISCUSSION}

In two extensive reviews of non-living models in microsurgical simulation training, Chan et al. [10] and Ilie et al. [17] evaluated 21 and 17 models respectively, with a detailed analysis of the various validities, advantages and limitations of each. While microscope set up, basic suturing, anastomosis techniques and a 
real tissue experience were well covered by several of these models, the principles of free tissue architecture, physiology and transfer were only considered possible in live animal models [10]. The chicken thigh adductor profundus free flap model described and validated here in the context of a non-living simulation course, suggests that that is not entirely the case. The anatomy and fine dissection skills required for a trainee to elevate, dissect the pedicle of the ischiatic chicken thigh vessels and further the finer skills required to dissect the muscle branch giving off the perforator to the adductor profundus has not been previously used in early stages of simulation training. Adductor profundus is a muscle in the inner thigh, easily accessible and is aligned by two avascular muscle raphe. Is has constant perforator in the posterior aspect always leading to a small calibre muscle branch connecting to the ischiatic pedicle. It can be used for basic training free flap elevation based on the ischiatic pedicle or submillimeter calibre advanced training based on the muscle branch pedicle. Trainees of various levels, with objectively assessed to show improvement in their microsurgical skills, found the model valuable.

The fresh chicken tissue is a simple, readily available and robust microsurgical non-living training model [9]. It has consistently been used for microvascular anastomosis training [9]; however, it has not been fully utilised for teaching the skills necessary for more macro- tissue dissection or free tissue transfer in

\section{Fig. 7. Sub-millimeter vessels (pre-anastomoses) \\ The vascular anatomy of the adductor profundus muscular pedicle. Distal pedicle ligation (red lines) allow free muscle transfer and anastomosis of both artery and vein (blue circles).}

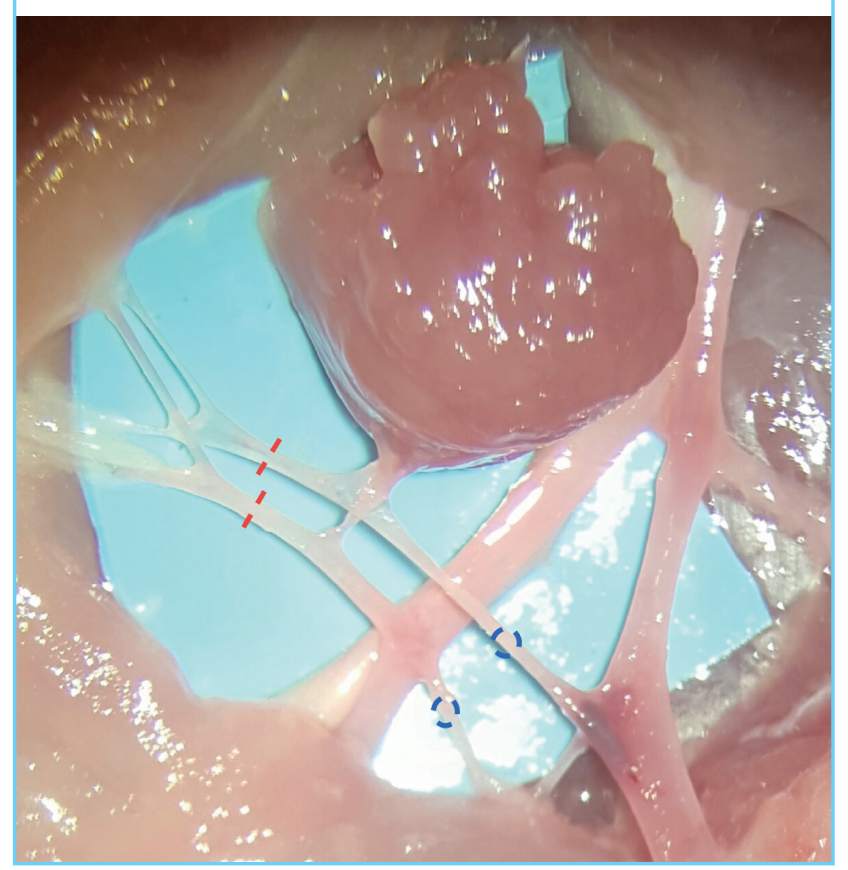

the early stages of microsurgical training. The chicken thigh abductor profundus free muscle flap is based on the muscular branches of the ischiatic pedicle, which supply other muscles in the posterior thigh necessitating careful dissection of the adductor profundus (AP) muscular branch, and control other branches. The anatomy of these muscle branches allows a horizontal, easily accessible platform to dissect either ischial vessels while maintaining a free muscle flap connected to this system. Harvesting the abductor profundus from the muscle branches originating from the ischial pedicle is submillimeter simulation task, considered as supermicrosurgical technique therefore for early microsurgery training we suggested the pedicle of this model to extend towards the larger calibre ischial vessels (Figs. 7,8) Reanastomosis a free chicken abductor profundus muscle flap was able to be achieved in different chicken thigh, interchanging within the cohort of each course cohorts.

The model expands on the techniques taught using the fresh chicken thigh to include: abductor profundus muscle identification by more macro-dissection, vascular pedicle micro-dissection, perforator-like pedicle handling, as well as microanastomosis with variable pedicle caliber and length. The model has a consistent anatomy and can be easily taught and performed to introduce the principles of free tissue transfer in a basic microsurgery curriculum prior to a living model. Feedback from trainees who were trained on this model confirmed a high level of satisfaction with the fidelity and utility of the AP free muscle flap based on the ischial pedicle. This feedback suggests that the

\section{Fig. 8. Sub-millimeter vessels (post-anastomoses)}

The adductor profundus (AP) muscle flap after free tissue transfer with both artery and vein anastomosis performed on the AP muscular pedicle.

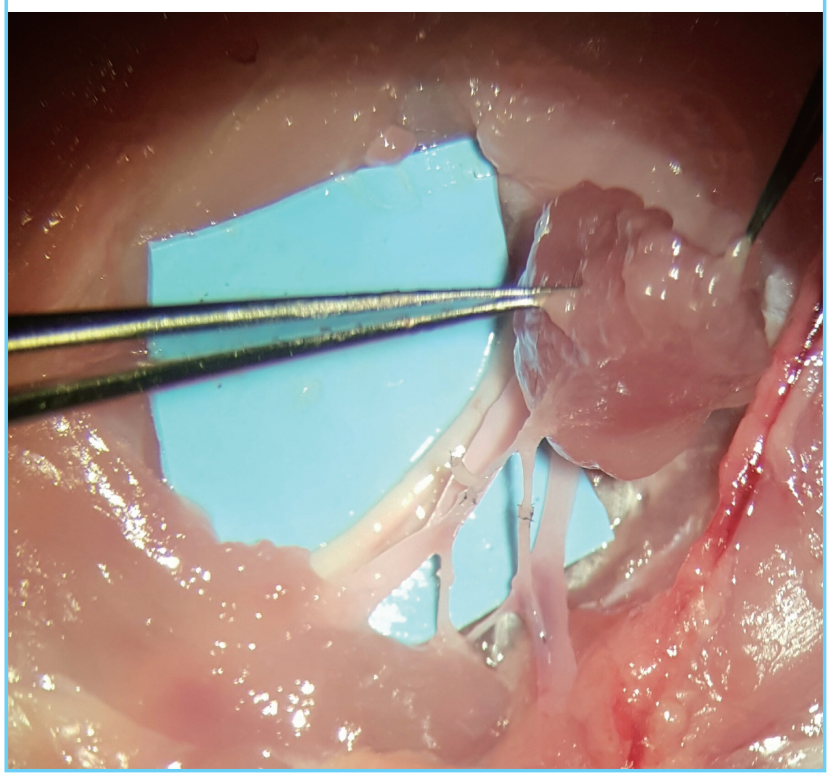


AP free muscle flap has high face validity for the principles of microvascular free tissue transfer.

The time to complete a microvascular anastomosis has been shown to be the most sensitive discriminator for microsurgery competency [18]. Dissection skills have not been fully validated in microsurgery simulation as the literature thus far addressed extensively the skills related to microvascular anastomosis. In our study, construct validity of microvascular anastomosis was confirmed with time to complete the arterial anastomosis significantly related to pre-existing skills. In addition, similar construct validity was demonstrated for tissue dissection with the more senior trainees being able to complete the AP free muscle flap in $20 \%$ less time than their less experienced counterparts. Accordingly, adding the flap dissection component to the arterial and venous anastomosis traditionally taught on the fresh chicken model, a more realistic simulation of free tissue transfer is possible with the same level of validity [9].

In this experiment, attending a 5-day microsurgery course allowed surgeons at various skill levels to improve the time required to perform the anastomosis as well as reduce the number of errors in their end products. This finding confirms the concurrent validity of the fresh chicken tissue as a model to teach microsurgery skills $[1,9,10]$. It was interesting to note that in this cohort, the ALI score of the pre-test was similar between the three cohorts. The ALI score was found to differentiate between levels of microvascular anastomosis skill in a previous cohort [16]. After the completion of the course, we observe that the senior trainees were able to make faster progress on their end product errors elimination and the ALI score showed construct validity at the post-test results. This could be explained by the lack of regular microsurgery exposure to this group of senior trainees. Microsurgeons who do not regularly practice to maintain their skills will experience a degree of skill loss that can be easily overcome with top up training [19]. Although an incidental finding, this highlights the importance of regular deliberate practice for both trainees and qualified microsurgeons in order to maintain a high level of skills [20].

Although trainees performing this microsurgical task gain understanding of careful dissection, identifying the perforator-like branch, and raising the free muscle flap, this version of a muscle free flap with a dominant muscle branch vessel is limited by lack of blood circulation. All non-living models of microsurgery training share this limitation. Another limitation of this model is the unique anatomy of this AP muscle that does not correlate with similar anatomical structure in a cadaveric human model or a living porcine training model. However, this new model presents an excellent tool to introduce a junior microsurgeon to the principles of free tissue transfer with high fidelity tactile feedback that would enhance the precision of movements required for the dissection of a perforator vessel. Furthermore, implementing this model in early stages of microsurgery training where trainees are taken through the procedure of dissecting and raising an entire free muscle flap in a step-by-step approach, could potentially have predictive validity with trainees reducing unnecessary mistakes on a living model leading to refinement as well reduction of the use of animals in this domain. Establishing the predictive validity of this model and its direct translation to animal simulation points a clear future direction.

The final outcome of this exercise is the microvascular anastomosis; based either on the ischial vessels for microsurgery training or based on the muscle branch which presents the constant perforator to abductor profundus muscle flap. Objective measure to evaluate the trainees' performance in this experiment demonstrated by the ALI scores, however the use of fluid infusion to overcome the lack of flow in non-living models has been previously described. In our model, we have observed that using serous fluid or artificial blood is not a helpful assessment method to establish objectively the quality of the final end-product. Moreover, pilot experience with liquid latex, simulating arterial (red/pink) and venous (blue) has been promising to subjectively demonstrate the presence of flow in both arterial and venous flap pedicles (Fig. 9, Supplemental Videos S1, S2). Nevertheless, the educational value of the ALI score to produce constructive feedback for technical errors was not able to be replaced by fluid infusion methodologies.

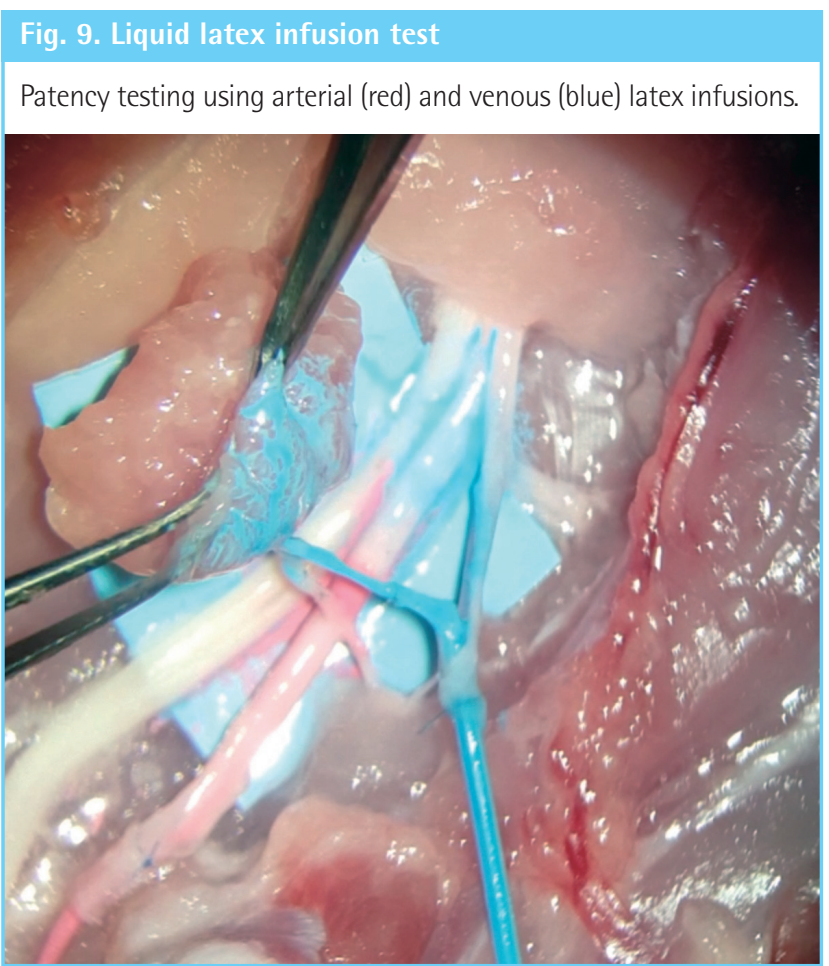


Ultimately, this model was designed in the context of the 3Rs in biomedical sciences and surgical education [4]. The model's construct validity and potential predictive validity could have wide ramifications for the use of the living model in microsurgery training. The differences in flap dissection detected in different skill level in this model may accurately predict the precision of a surgeon operating on a living model. Therefore, in the future, trainees may be required to reach a benchmark for each of the three parameters of the non-living model free tissue transfer assessed in this study, namely: flap dissection, microvascular anastomosis and quality of the end product, before proceeding to the living model in their training. In this way, the chicken thigh AP free muscle flap model could act as a stepping-stone in the microsurgical curriculum learning curve. Completing training on this model may enhance training on a living model, as trainees will be better equipped to deal with the additional challenges that accompany performing a perforator-like pedicle dissection or free flap procedure on a living biological model. This model would therefore realize all of the 3Rs tenets: refinement, replacement and reduction of the use of living animals in training without sacrificing the quality of education of trainee microsurgeons. Moreover, the educational value of the super microsurgery AP free muscle flap requires further investigation for its validated use to be established [21].

The chicken thigh adductor profundus free muscle flap model demonstrates face and construct validity when used to introduce microsurgery trainees to the principles of free tissue transfer. The model can improve surgeons' microsurgical skills when introduced at the early stages of the learning curve as well as replace, reduce and refine the use of live animals in microsurgical training. The low cost, constant, and reproducible anatomy makes this model a recommended addition to any microsurgical training curriculum.

\section{REFERENCES}

1. Singh M, Ziolkowski N, Ramachandran S, et al. Development of a five-day basic microsurgery simulation training course: a cost analysis. Arch Plast Surg 2014;41:213-7.

2. Fanua SP, Kim J, Shaw Wilgis EF. Alternative model for teaching microsurgery. Microsurgery 2001;21:379-82.

3. Shurey S, Akelina Y, Legagneux J, et al. The rat model in microsurgery education: classical exercises and new horizons. Arch Plast Surg 2014;41:201-8.

4. Russell WMS, Burch RL. The principles of humane experimental technique. London: Methuen; 1959.

5. Lannon DA, Atkins JA, Butler PE. Non-vital, prosthetic, and virtual reality models of microsurgical training. Micro- surgery 2001;21:389-93.

6. Abla AA, Uschold T, Preul MC, et al. Comparative use of turkey and chicken wing brachial artery models for microvascular anastomosis training. J Neurosurg 2011;115:1231-5.

7. Colpan ME, Slavin KV, Amin-Hanjani S, et al. Microvascular anastomosis training model based on a Turkey neck with perfused arteries. Neurosurgery 2008;62:ONS407-10.

8. Lausada NR, Escudero E, Lamonega R, et al. Use of cryopreserved rat arteries for microsurgical training. Microsurgery 2005;25:500-1.

9. Marsh DJ, Norton SE, Mok J, et al. Microsurgical training: the chicken thigh model. Ann Plast Surg 2007;59:355-6.

10. Chan WY, Matteucci P, Southern SJ. Validation of microsurgical models in microsurgery training and competence: a review. Microsurgery 2007;27:494-9.

11. Erman AB, Deschler DG. The chicken thigh model for head and neck microvascular training. Laryngoscope 2011;121 (SUPPL 4). http://doi.org/10.1002/lary.21990.

12. Hino A. Training in microvascular surgery using a chicken wing artery. Neurosurgery 2003;52:1495-7.

13. Kim BJ, Kim ST, Jeong YG, et al. An efficient microvascular anastomosis training model based on chicken wings and simple instruments. J Cerebrovasc Endovasc Neurosurg 2013;15: 20-5.

14. Satterwhite T, Son J, Echo A, et al. The chicken foot dorsal vessel as a high-fidelity microsurgery practice model. Plast Reconstr Surg 2013;131:311e-312e.

15. Mathes SJ, Nahai F. Clinical atlas of muscle and musculocutaneous flaps. St. Louis; London: Mosby; 1979.

16. Ghanem AM, Al Omran Y, Shatta B, et al. Anastomosis lapse index (ALI): a validated end product assessment tool for simulation microsurgery training. J Reconstr Microsurg 2016;32:233-41.

17. Ilie VG, Ilie VI, Dobreanu C, et al. Training of microsurgical skills on nonliving models. Microsurgery 2008;28:571-7.

18. Starkes JL, Payk I, Jennen P, et al. Chapter 12 A stitch in time: cognitive issues in microsurgery. In: Starkes JL, Allard F, editors. Advances in psychology. Amsterdam: Elsevier; 1993. p.225-40.

19. Madada-Nyakauru R, Ghanem A, Malzone G, et al. Microsurgery skill retention: implications for continuous professional development and revalidation. Proceeding of the 12th Congress of the European Federation of Societies for Microsurgery (EFSM) and the 15th National Congress of the Spanish Association of Microsurgery; 2014 Apr 3-5; Barcelona, Spain.

20. Ghanem AM, Hachach-Haram N, Leung CC, et al. A systematic review of evidence for education and training inter- 
ventions in microsurgery. Arch Plast Surg 2013;40:312-9.

21. Chen WF, Eid A, Yamamoto T, et al. A novel supermicrosur- gery training model: the chicken thigh. J Plast Reconstr Aesthet Surg 2014;67:973-8.

Supplemental Video S1. Arterial latex infusion.

Supplemental data can be found at: http://e-aps.org/src/sm/aps-44-293-s001.mp4

Supplemental Video S2. Venous latex infusion.

Supplemental data can be found at: http://e-aps.org/src/sm/aps-44-293-s002.mp4 